\title{
Vitamin D (Cholecalciferol) with Low Dose Vitamin C as a Safe and Effective Therapeutic Modality in an Adult with COVID-19 Pneumonia
}

\author{
Shahan Waheed, Rana Osama Zahid, Summaiya Tauseeq Khan, Faysal Subhani and Emaduddin Siddiqui \\ Department of Emergency Medicine, Aga Khan University Hospital, Karachi, Pakistan
}

\begin{abstract}
This is a case of an elderly female presenting with fever, cough and shortness of breath. On presentation, she had tachypnea and an oxygen requirement of 2 liters through nasal prongs. Her investigations were suggestive of COVID-19 pneumonia with bilateral ground-glass appearance on chest X-ray and a positive nasopharyngeal PCR swab. She had low vitamin D levels on presentation and was given 200,000 units of cholecalciferol, once daily for 3 days with Vitamin C, $500 \mathrm{mg}$ per oral once daily for 7 days. Her symptoms got progressively better and her oxygen requirement diminished on next day. On day 3 , her symptoms completely resolved, and her chest X-ray improved. In patients with COVID-19 pneumonia, who are vitamin D deficient, administration of large doses of cholecalciferol for few days can be a safe option to treat mild to moderate COVID-19 pneumonia.
\end{abstract}

Key Words: Vitamin D, COVID-19, Pneumonia, Vitamin C.

How to cite this article: Waheed S, Zahid RO, Khan ST, Subhani F, Siddiqui E. Vitamin D (Cholecalciferol) with Low Dose Vitamin C as a Safe and Effective Therapeutic Modality in an Adult with COVID-19 Pneumonia. J Coll Physicians Surg Pak 2021; 31(JCPSPCR):CR90CR92.

\section{INTRODUCTION}

Novel coronavirus disease 2019 (COVID-19) is on the rise and many treatments are under use; tocilizumab, convalescent plasma, hydroxychloroquine, remedisivir, etc. but none showing promising effects in treating COVID-19 pneumonia. ${ }^{1-3}$ Vitamin $D$ (cholecalciferol) plays a pivotal role in calcium and phosphate homeostasis, which affects bone growth. ${ }^{4}$ The association of low vitamin D levels with increased susceptibility to upper respiratory tract infections is a known efact. ${ }^{5}$ Meta-analyses have shown that patients with low 25-hydroxyvitamin D concentrations gained most benefit in the treatment. ${ }^{6,7}$

The cross-sectional analysis of COVID-19 mortality in Europe has shown that patients had deficient vitamin D levels. ${ }^{8}$ The role of vitamin D in protection against COVID-19 pneumonia is hypothesised due to development of antimicrobial peptides in the respiratory epithelium and decreased inflammatory response to infection. ${ }^{9}$

\section{CASE REPORT}

A60-year woman presented to the Emergency Room with fever, shortness of breath and occasional cough for 7 days.

Correspondence to: Dr. Shahan Waheed, Department of Emergency Medicine, The Aga Khan University Hospital, Karachi, Pakistan

E-mail: docshahan83@hotmail.com

Received: November 26, 2020; Revised: March 06, 2021; Accepted: March 11, 2021
DOI: https://doi.org/10.29271/jcpsp.2021.JCPSPCR.CR90

The vitals at presentation were blood pressure $110 / 60 \mathrm{mmHg}$, pulse 120 beats per minute, oxygen saturation $85 \%$ on room air, and temperature of $39^{\circ} \mathrm{C}$. On physical examination, a clear observation of tachypnea, dehydration, pallor and bibasilar crepitations on chest auscultation were appreciated. Nasopharyngeal swab of COVID-19 on PCR was positive.

The management started with oxygen, intravenous paracetamol, blood tests and chest X-ray. Blood tests showed raised white blood cells, C-reactive protein (CRP), ferritin and low vitamin D levels. Chest X-ray showed bilateral ground-glass appearance with pulmonary edema (Figure 1 ). She was given levofloxacin, furosemide, intramuscular vitamin D3, 200,000 units and oral vitamin C, $500 \mathrm{mg}$. She was advised to continue with same treatment for the next 3 days with home oxygen, awake proning and vitamin D3, 200,000 units, every day for the next 2 days. On follow-up in 24 hours, her symptoms got better. Oxygen requirement dropped to one liter. On $3^{\text {rd }}$ day, she was considerably better with oxygen saturation of $97 \%$ on room air and no temperature (Table I). Repeatchest $X$-ray showed significant improvement in lower zone infiltrates (Figure 2). She regained normal functionality at day 8 ; and follow-up after 2 weeks, showed no symptoms and no side effects.

\section{DISCUSSION}

This case highlights a very serious and lethal manifestation of COVID-19 infection. This case is unique in which we opted a treatment regimen for a patient with moderate symptoms of 
COVID-19 pneumonia with home oxygen and pronning protocol. The patient's symptoms drastically improved with diminished requirement of oxygen in two days.

Table I: Inflammatory markers and oxygen saturation levels pre- and post-vitamin D (cholecalciferol) and vitamin C administration.

\begin{tabular}{|c|c|c|c|}
\hline & Day 1 & Day 2 & Day 3 \\
\hline C-reactive protein & $220 \mathrm{mg} / \mathrm{L}$ & $180 \mathrm{mg} / \mathrm{L}$ & $90 \mathrm{mg} / \mathrm{L}$ \\
\hline Ferritin & $525 \mu \mathrm{g} / \mathrm{L}$ & $320 \mu \mathrm{g} / \mathrm{L}$ & $110 \mu \mathrm{g} / \mathrm{L}$ \\
\hline Oxygen saturation & 88\% (5 liters oxygen facemask) & 92\% (1 liter oxygen nasal prong) & 97\% (room air) \\
\hline
\end{tabular}

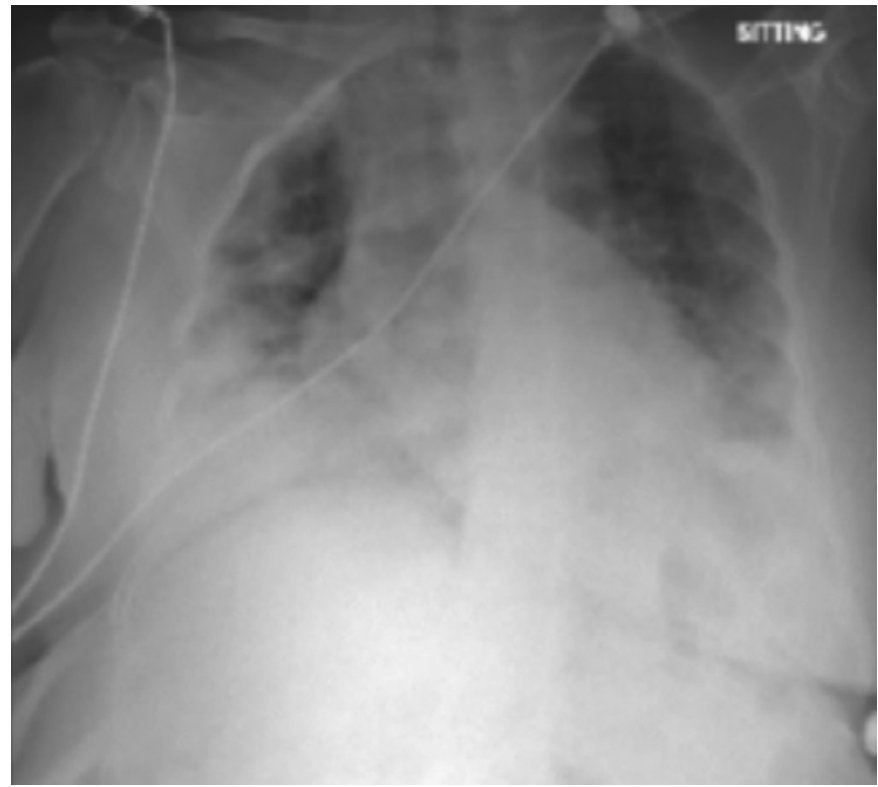

Figure 1: Chest X-ray at presentation, showed bilateral ground-glass appearance, typical for COVID 19 pneumonia.

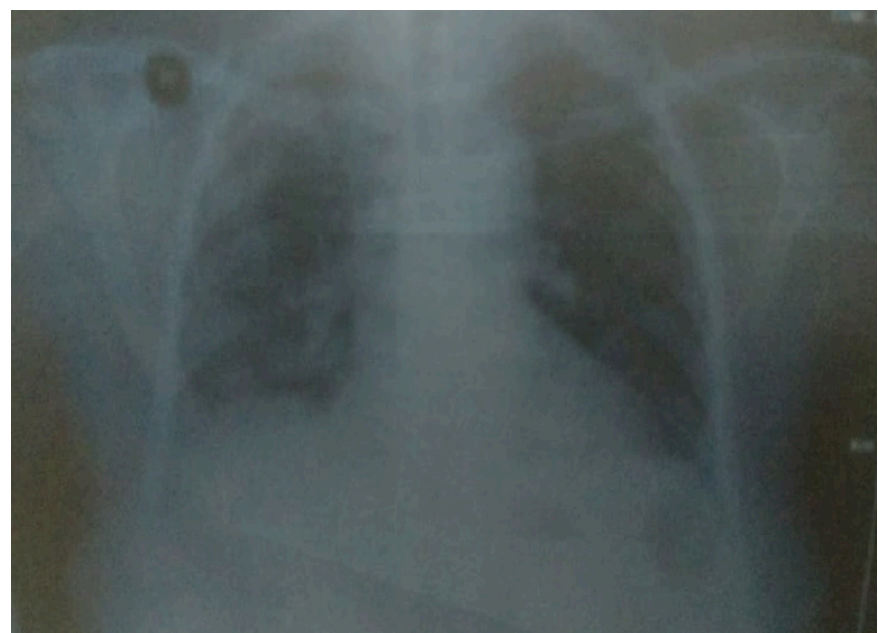

Figure 2: Chest X-ray at day 3 after Vitamin D3 and Vitamin C supplementation, showing improvement of ground-glass appearance.

The putative mechanism of vitamin $D$ could be hypothesised to be three-fold. First, as it is reported that vitamin D supports the development of antimicrobial peptides in the respiratory epithelium, making infection with the virus and development of symptoms less severe. Second, it also helps in mitigation of the inflammatory response to infection and; hence, progression to cytokine storm, which is one of the worse complications of COVID-19 infection. Third, vitamin D promotes the expression of angiotensin converting enzyme 2 gene that is one of the receptors that down-regulates due to SARS-COV-2 infection.

The combination of vitamin D3 with vitamin C may have composite effect in diminishing the disease progress. It is reported that vitamin $D$ levels are low in the worst affected countries of the world, such as US, UK, China and Iran, which may be a harbinger of poor outcome. Resolution of the inflammatory markers like CRP and ferritin can be due to its role in suppressing IL-6. This case is important as we did not use steroids or any antivirals, which may have an immunosuppressive effect altering the CRP and ferritin levels.

This treatment is important in developing nations, compared to expensive antivirals. As our patient was vitamin D deficient, replacement of vitamin $D$ may have played a putative role in improving outcomes. A study by Jain et al. found increased mortality in patients with vitamin $D$ deficiency. ${ }^{9}$ Additionally, the beneficial effects are very similar to reports published by Pinzon et al. ${ }^{10}$

Previous studies have reported efficacy of vitamin $D$ in respiratory tract infections; but in COVID-19 pneumonia, the evidence is scare. The combination of vitamin D and C, along with oxygen and pronning may prove to be beneficial in treating patients effectively at home with moderate pneumonia.

\section{PATIENT'S CONSENT:}

Informed and written consent was taken form the patient to publish the data.

\section{CONFLICT OF INTEREST:}

The authors declared no conflict of interest.

\section{AUHORS' CONTRIBUTION:}

SW, ROZ, ST, FS: Was involved in identification, clinical care and write up of the manuscript. ES: Was involved in critical review and write up of the manuscript.

\section{REFERENCES}

1. Cortegiani A, Ingoglia G, Ippolito M, Giarratano A, Einav S. A systematic review on the efficacy and safety of chloroquine for the treatment of COVID-19. J Criticalcare 2020; 57:279-283.doi: 10.1016/j.jcrc.2020.03.005.

2. Molina JM, Delaugerre C, Le Goff J, Mela-Lima B, Ponscarme $D$, Goldwirt L, et al. No evidence of rapid antiviral clearance or clinical benefit with the combination of hydroxy-chloroquine and azithromycin in patients with severe COVID-19 infection. Med Mal Infect 2020; 50(4):384. 10. doi: 
10.1016/j.medmal.2020.03.006.

3. Chan KW, Wong VT, Tang SCW. COVID-19: An update on the epidemiological, clinical, preventive and therapeutic evidence and guidelines of integrative Chinese-Western medicine for the management of 2019 novel coronavirus disease. J Chin Medicine 2020; 48(03):737-62. doi: 10.1142/S0192415X20500378.

4. Daneshkhah A, Agrawal V, Eshein A, Subramanian H, Roy HK, Backman V. The possible role of Vitamin D in suppressing cytokine storm and associated mortality in COVID-19 patients. Medrxiv 2020; doi.org/10.1101/ 2020.04.08.20058578.

5. Marik PE, Kory $P$, Varon J. Does vitamin D status impact mortality from SARS-CoV-2 infection? Medicine in Drug Discovery 2020; 6:100041 doi: 10.1016/j.medidd.2020. 100041.

6. Grant WB, Lahore $\mathrm{H}, \mathrm{McD}$ onnell SL, Baggerly CA, French CB, Aliano JL, et al. Vitamin D supplementation could prevent and treat influenza, coronavirus, and pneumonia infections 2020; doi: 10.20944/preprints202003.0235.v1

7. Grant WB, Lahore $\mathrm{H}, \mathrm{McD}$ onnell $\mathrm{SL}$, Baggerly CA, French CB, Aliano JL, et al. Evidence that vitamin D supplementation could reduce risk of influenza and COVID-19 infections and deaths. Nutrients 2020; 12(4): 988.

8. Daneshkhah A, Eshein A, Subramanian H, Roy HK, Backman $\mathrm{V}$. The role of vitamin $\mathrm{D}$ in suppressing cytokine storm in COVID-19 patients and associated mortality. Medrxiv 2020; doi.org/10.1101/2020.04.08.20058578

9. Jain A, Chaurasia R, Sengar NS. Analysis of vitamin D level among asymptomatic and critically ill COVID-19 patients and its correlation with inflammatory markers. Sci Rep 2020; 10(1):20191 doi: 10.1038/s41598-020-77093-z.

10. Pinzon RT, Angela \& Pradana AW. Vitamin D deficiency among patients with COVID-19: case series and recent literature review. Trop Med Health 48(1):102. doi: 10.1186/ s41182-020-00277-w. 